The endocytic pathways of a secretory granule membrane protein in HEK293 cells : PAM and EGF traverse a dynamic multivesicular body network together

\title{
Back, Nils
}

2017-08

Back, N , Kanerva , K , Kurutihallib , V , Yanik , A, Ikonen, E, Mains, R E \& Eipper , B A 2017 , ' The endocytic pathways of a secretory granule membrane protein in HEK293 cells : PAM and EGF traverse a dynamic multivesicular body network together ' , European Journal of Cell Biology, vol. 96 , no. 5 , pp. 407-417 . https://doi.org/10.1016/j.ejcb.2017.03.007

http://hdl.handle.net/10138/298059

https://doi.org/10.1016/j.ejcb.2017.03.007

publishedVersion

Downloaded from Helda, University of Helsinki institutional repository.

This is an electronic reprint of the original article.

This reprint may differ from the original in pagination and typographic detail.

Please cite the original version. 
Research paper

\title{
The endocytic pathways of a secretory granule membrane protein in HEK293 cells: PAM and EGF traverse a dynamic multivesicular body network together
}

\author{
Nils Bäck ${ }^{\mathrm{a}, *}$, Kristiina Kanerva ${ }^{\mathrm{a}}$, Vishwanatha Kurutihalli ${ }^{\mathrm{b}}$, Andrew Yanik ${ }^{\mathrm{b}}$, \\ Elina Ikonen ${ }^{\mathrm{a}}$, Richard E. Mains ${ }^{\mathrm{b}}$, Betty A. Eipper ${ }^{\mathrm{b}}$ \\ a Department of Anatomy, Faculty of Medicine, University of Helsinki, Helsinki, Finland \\ ${ }^{\mathrm{b}}$ Department of Neuroscience, University of Connecticut Health Center, Farmington, CT, USA
}

\section{A R T I C L E I N F O}

\section{Article history:}

Received 3 January 2017

Received in revised form 22 March 2017

Accepted 22 March 2017

\section{Keywords:}

Exosome

Intraluminal vesicle

Ectosome

MPR

EGFR

Peptidylglycine alpha-amidating

monooxygenase

Live cell imaging

\begin{abstract}
A B S T R A C T
Peptidylglycine $\alpha$-amidating monooxygenase (PAM) is highly expressed in neurons and endocrine cells, where it catalyzes one of the final steps in the biosynthesis of bioactive peptides. PAM is also expressed in unicellular organisms such as Chlamydomonas reinhardtii, which do not store peptides in secretory granules. As for other granule membrane proteins, PAM is retrieved from the cell surface and returned to the trans-Golgi network. This pathway involves regulated entry of PAM into multivesicular body intralumenal vesicles (ILVs). The aim of this study was defining the endocytic pathways utilized by PAM in cells that do not store secretory products in granules. Using stably transfected HEK293 cells, endocytic trafficking of PAM was compared to that of the mannose 6-phosphate (MPR) and EGF (EGFR) receptors, established markers for the endosome to trans-Golgi network and degradative pathways, respectively. As in neuroendocrine cells, PAM internalized by HEK293 cells accumulated in the trans-Golgi network. Based on surface biotinylation, $>70 \%$ of the PAM on the cell surface was recovered intact after a $4 \mathrm{~h}$ chase and soluble, bifunctional PAM was produced. Endosomes containing PAM generally contained both EGFR and MPR and ultrastructural analysis confirmed that all three cargos accumulated in ILVs. PAM containing multivesicular bodies made frequent dynamic tubular contacts with younger and older multivesicular bodies. Frequent dynamic contacts were observed between lysosomes and PAM containing early endosomes and multivesicular bodies. The ancient ability of PAM to localize to ciliary membranes, which release bioactive ectosomes, may be related to its ability to accumulate in ILVs and exosomes.
\end{abstract}

(c) 2017 Elsevier GmbH. All rights reserved.

\section{Introduction}

Peptidylglycine $\alpha$-amidating monooxygenase (PAM), a cuproenzyme, is best known for its essential role in the biosynthesis of the many $\alpha$-amidated peptides stored in secretory granules and released by neurons and endocrine cells in response to specific signals. A bifunctional integral membrane enzyme, intact

Abbreviations: CSFM, complete serum-free medium; EGF, epidermal growth factor; HEK, human embryonic kidney; HSG, HEPES-buffered saline with glucose; ILV, intralumenal vesicle; MPR, mannose-6-phosphate receptor; PAM, peptidylglycine $\alpha$-amidating monooxygenase; PAL, peptidyl- $\alpha$-hydroxyglycine $\alpha$-amidating lyase; PHM, peptidylglycine $\alpha$-hydroxylating monooxygenase; CrPAM, Chlamydomonas reinhardtii PAM.

* Corresponding author at: Department of Anatomy, Faculty of Medicine, POB 63, 00014 University of Helsinki, Finland.

E-mail address: nils.back@helsinki.fi (N. Bäck).
PAM protein is deposited on the cell surface during the process of granule exocytosis. Governed by trafficking determinants in its cytosolic domain, PAM is retrieved from the cell surface by clathrin-mediated endocytosis and can be returned to the transGolgi network or degraded. Endoproteolytic cleavages in the linker regions connecting the catalytic cores of PAM can occur in secretory granules, generating catalytically active soluble fragments that are released along with the product peptides (reviewed in Kumar et al., 2016a).

It is now clear that expression of PAM is not limited to neurons and endocrine cells. Expression of various preprohormones and monoclonal antibodies in cell lines that do not form secretory granules consistently demonstrates that the low levels of PAM activity detected in these cells are sufficient to amidate peptidylglycine substrates as they pass through the secretory pathway. In addition, it is now known that PAM is expressed in Chlamydomonas reinhardtii, a unicellular green alga. The localization of CrPAM (Chlamydomonas 
reinhardtii PAM) to the Golgi complex and to the ciliary membrane led to the identification of PAM in both motile and primary cilia in mammals (Kumar et al., 2016b).

Protein trafficking through the endocytic pathway in HEK293 cells, which engage in constitutive secretion but do not produce secretory granules, has been studied in great detail. Stable expression of rat PAM-1 in HEK293 cells demonstrated production of active enzyme that cycled onto and off of the plasma membrane (Tausk et al., 1992; Milgram et al., 1993). These well characterized cells provide an ideal system for focusing on the endocytic trafficking of PAM.

In AtT-20 cells, PAM protein internalized from the plasma membrane rapidly appears in the intralumenal vesicles (ILVs) of multivesicular bodies (Bäck et al., 2010). Protein entry into ILVs generally leads to lysosomal degradation, as best shown for EGF and the EGF receptor (Gruenberg and Stenmark, 2004; Tomas et al., 2014). The mechanism for delivery of ILVs to lysosomes remains a question of debate (Bright et al., 2005; Gan et al., 2009; Pryor and Luzio, 2009). PAM routed to ILVs largely escapes lysosomal degradation (Bäck et al., 2010), as has been observed for tetraspanins (Gruenberg and Stenmark, 2004), MHC class II proteins (Kleijmeer et al., 2001) and the cation independent mannose-6-phosphate receptor (Kobayashi et al., 1998).

The aim of this study was to determine the endocytic pathway taken by PAM-1 internalized from the surface of stably transfected HEK293 cells and to compare PAM trafficking to the routes taken by EGF/EGF receptor complexes and by cation independent mannose6-phosphate receptors, markers for degradative and endosome to trans-Golgi network trafficking, respectively.

\section{Materials and methods}

\subsection{Cells}

HEK293 cells stably transfected with vector encoding rat PAM1 (Tausk et al., 1992; Milgram et al., 1993) were maintained in a $5 \% \mathrm{CO}_{2}$ atmosphere in Dulbecco's modified Eagle's medium (DMEM)/F12 supplemented with 25 mM HEPES, 100 units/ml penicillin, $100 \mu \mathrm{g} / \mathrm{ml}$ streptomycin, $10 \%$ fetal calf serum and $0.5 \mathrm{mg} / \mathrm{ml}$ G418 and passed weekly. Complete serum-free medium (CSFM) is the same medium without serum but with insulin-transferrinselenium (Life Sciences).

\subsection{Surface biotinylation}

HEK293 cells stably expressing rat PAM-1 (Tausk et al., 1992; Milgram et al., 1993) were incubated for $30 \mathrm{~min}$ at $37^{\circ} \mathrm{C}$ in CSFM. Before labeling with cell impermeant sulfo-NHS-LC-biotin, cells were rinsed with $15 \mathrm{mM}$ HEPES, $120 \mathrm{mM} \mathrm{NaCl}, 2 \mathrm{mM} \mathrm{CaCl}_{2}, 4 \mathrm{mM}$ $\mathrm{KCl}, 25 \mathrm{mM}$ glucose, pH 7.5 (HSG). For assessing steady state plasma membrane localization, surface biotinylation was carried out on ice and all solutions used were pre-chilled. For assessment of endocytic trafficking, surface biotinylation was carried out for $10 \mathrm{~min}$ at $37^{\circ} \mathrm{C}$. Sulfo-NHS-LC-biotin (1.25 mM dissolved in HSG)(Pierce) was applied on ice or at $37^{\circ} \mathrm{C}$. The reaction was quenched by replacing the biotin-containing HSG with $2 \mathrm{mg} / \mathrm{ml}$ BSA in CSFM (quenching medium); after $5 \mathrm{~min}$, the quenching medium was replaced with CSFM. Cells were either extracted immediately (Pulse) or incubated in CSFM containing $1 \mathrm{mg} / \mathrm{ml}$ BSA for up to $4 \mathrm{~h}$ (Chase). Cells were extracted into $20 \mathrm{mM}$ Na TES, $10 \mathrm{mM}$ mannitol, $1 \% \mathrm{TX}-100$, $\mathrm{pH} 7.4$ (TMT) supplemented with protease inhibitors $(30 \mu \mathrm{g} / \mathrm{ml}$ phenylmethylsulfonyl fluoride, $2 \mu \mathrm{g} / \mathrm{ml}$ leupeptin, $2 \mu \mathrm{g} / \mathrm{ml}$ pepstatin and $16 \mu \mathrm{g} / \mathrm{ml}$ benzamidine) and particulate material was removed by centrifugation at $14,000 \mathrm{rpm}$ for $20 \mathrm{~min}$. After centrifugation of chase media, protease inhibitors were added. Clarified lysates and media were incubated with neutravidin beads $(40 \mu \mathrm{l}$ slurry) (Pierce) for $1 \mathrm{~h}$ at $4{ }^{\circ} \mathrm{C}$. Beads were rinsed twice with TMT containing protease inhibitors and once with buffer lacking detergent before elution into Laemmli sample buffer by heating for $5 \mathrm{~min}$ at $95{ }^{\circ} \mathrm{C}$. Eluates and the corresponding inputs were analyzed on 4-15\% gradient gels and non-saturated images were quantified using SynGene software.

\subsection{Antibodies}

The following antibodies were used: rabbit polyclonal JH629 [rPAM-1(394-498), exon A (Yun et al., 1995)], mouse monoclonal anti-syntaxin 6 (ab 610635, BD Transduction Laboratories), mouse monoclonal anti-mannose-6-phosphate receptor (cation independent)(2G11, Abcam), mouse monoclonal anti-EGFR antibody (ab30, Abcam). Alexa Fluor 555 or 488 labeled JH629 antibody was prepared using affinity purified antibody and APEX antibody labeling kits (Molecular Probes) according to the protocol provided by the manufacturer. For uptake studies EGF, biotinylated, complexed to Alexa Fluor 555 or 488 streptavidin (Molecular Probes; E35350, E13345) or dextran, Alexa Fluor 488 or 568, 10,000 MW, final concentration $50 \mu \mathrm{g} / \mathrm{ml}$ (Molecular Probes; D22910, D22912) were used.

\subsection{Immunofluorescence and live cell imaging}

For uptake studies, cells were kept in DMEM-HEPES containing $1 \%$ BSA, incubated with antibody to the Exon 16 region of PAM, JH629 1:2000, antibody to MPR (used at $2 \mu \mathrm{g} / \mathrm{ml}$ ) or EGF Alexa Fluor 488 or $5558 \mu \mathrm{g} / \mathrm{ml}$ at $37^{\circ} \mathrm{C}$ for $5 \mathrm{~min}$, then chased in culture medium. The cells were fixed with $4 \%$ paraformaldehyde, initially on ice, and permeabilized with $0.2 \%$ Triton-X100. Cells were either first incubated with primary antibody (syntaxin 6 antibody) for $1 \mathrm{~h}$, then Alexa Fluor conjugated secondary antibody for $1 \mathrm{~h}$, or only Alexa Fluor conjugated secondary antibodies for $1 \mathrm{~h}$. The cells were photographed with a Leica TCS SP8 confocal microscope with a $65 \times$ oil immersion lens.

Confocal live cell imaging was performed on a Leica TCS SP8 attached to a DMI 6000 inverted microscope equipped with a full enclosure temperature controlled environmental chamber was used. The cells were grown in glass-bottom dishes (LabTek, Nunc) incubated in DMEM-HEPES + 1\% BSA with directly Alexa 488 or 555 labeled JH629 PAM antibody and Alexa 488 or 555 conjugated EGF $8 \mu \mathrm{g} / \mathrm{ml}$ for $10 \mathrm{~min}$, then chased in DMEM-HEPES + $1 \%$ BSA. Images were recorded with a $63 \times$ water immersion lens and data acquired with LAS AF 3 (Leica). Time-lapse images were obtained every $735 \mathrm{~ms}$ for $66 \mathrm{~s}$ (90 frames). Images were deconvoluted with Huygens Professional (SVI) and renderings made with Imaris 7.2 (Bitplane). For analysis of Pearson's and Mander's coefficients, the JACoP plugin of ImageJ (National Institutes of Health) was used. Colocalization analysis on individual endosomes was performed manually on the deconvoluted images. For analysis of contacts, randomly chosen PAM containing endosomes were traced manually frame by frame; the number of contacts during the period the endosome could be traced and the duration of contacts were quantified by recording the number of frames in which each contact was visible.

\subsection{Electron microscopy}

For colloidal gold labeling at the ultrastructural level, cells were incubated for $20 \mathrm{~min}$ at $4{ }^{\circ} \mathrm{C}$ with PAM antibody JH 629 (1:500) or MPR antibody $(16 \mu \mathrm{g} / \mathrm{ml})$ or EGFR antibody $(8 \mu \mathrm{g} / \mathrm{ml})$ and Alexa Fluor 555 EGF $(0.2 \mu \mathrm{g} / \mathrm{ml})$ in DMEM-HEPES-0.2\% BSA. They were rinsed in DMEM-HEPES-BSA at $4{ }^{\circ} \mathrm{C}$ and then incubated for $20 \mathrm{~min}$ at $4{ }^{\circ} \mathrm{C}$ with $10 \mathrm{~nm}$ colloidal gold conjugated goat anti-mouse IgG 
$(\mathrm{H}+\mathrm{L})$ or $5 \mathrm{~nm}$ colloidal gold conjugated goat anti-rabbit $\operatorname{IgG}(\mathrm{H}+\mathrm{L})$ (BBI Solutions) diluted 1:50 in DMEM-HEPES. They were again rinsed in DMEM-HEPES at $4{ }^{\circ} \mathrm{C}$ and then chased in culture medium at $37^{\circ} \mathrm{C}$. The cells were then fixed with $2.5 \%$ glutaraldehyde (Electron Microscopical Sciences) in $0.1 \mathrm{M}$ sodium cacodylate buffer and osmicated, dehydrated and embedded in Epon. Sections were poststained with uranyl acetate and lead citrate.

\subsection{High pressure freezing and freeze substitution}

High pressure freezing and freeze substitution were performed as described in Biazik et al. (2015), except that cells were cultured on $6 \mathrm{~mm}$ sapphire discs and the substitution medium included $0.1 \%$ uranyl acetate, $1 \%$ osmium tetroxide and $5 \%$ distilled water in acetone.

\section{Results}

\subsection{PAM is internalized to the TGN area in cells that do not produce secretory granules}

In mouse AtT-20 corticotropic tumor cells, newly synthesized PAM enters the TGN (Milgram et al., 1993), where it is incorporated into nascent secretory granules and subject to endoproteolytic cleavage by the same enzymes that cleave proopiomelanocortin. During secretory granule exocytosis, soluble PHM and soluble PAL are secreted, along with the products of POMC cleavage and intact membrane PAM is deposited on the cell membrane. PAM that appears on the cell surface is quickly internalized and routed to the intralumenal vesicles of multivesicular bodies in a process regulated by phosphorylation of the PAM cytoplasmic domain (Bäck et al., 2010).

HEK293 cells lack the prohormone convertases characteristic of neuroendocrine cells and do not produce secretory granules, making it possible to focus on steps in the endocytic trafficking of PAM that are shared by all cells. At steady state, most of the PAM- 1 in HEK293 cells is localized to the TGN, overlapping the distribution of syntaxin 6, a TGN marker (Fig. 1A) (Tausk et al., 1992). When PAM at the cell membrane was labeled with antibody and the antibody was internalized for $10-40 \mathrm{~min}$, we saw a progressive accumulation of internalized PAM/Ab complex in the area occupied by the TGN (Fig. 1B).

Better resolution is required to resolve the endocytic compartments traversed by PAM/Ab complexes internalized from the cell surface. For electron microscopy, we tagged PAM at the cell surface with PAM ectodomain antibody/protein A-gold complexes; after $20 \mathrm{~min}$, we detected internalized PAM/Ab complexes on the limiting membrane on multivesicular bodies and on intralumenal vesicles contained within multivesicular bodies (Fig. 1C).

\subsection{PAM routed to multivesicular bodies is not degraded}

In order to interpret the results of the PAM/Ab uptake experiments, we sought a quantitative means of evaluating the amount of PAM on the cell surface and the time course over which internalized PAM was degraded in HEK293 cells. Surface biotinylation was previously used to study this process in AtT-20 cells expressing PAM-1 (Bäck et al., 2010). As in HEK293 cells, PAM/Ab complexes internalized from the surface of AtT-20 mouse corticotrope tumor cells appear in the intralumenal vesicles of multivesicular bodies. Although ILV entry can lead to degradation, over half of the PAM biotinylated on the cell surface remained intact in AtT-20 cells expressing PAM-1 after a $1 \mathrm{~h}$ chase; after a $4 \mathrm{~h}$ chase, more than a third of the internalized PAM remained intact (Bäck et al., 2010; Milgram et al.,1993).
By carrying out the surface biotinylation reaction at low temperature, to block membrane trafficking, we determined the percentage of the total PAM-1 in HEK293 cells on the cell surface at steady state (Fig. 2A). Consistent with our immunofluorescence images, only $3.5+0.8 \%$ of the total PAM- 1 could be tagged with biotin under these conditions; thus about $3 \%$ of the PAM- 1 is on the surface of HEK293 cells at steady state.

We next incubated PAM-1 HEK293 cells with cell impermeant biotin for $10 \mathrm{~min}$ at $37^{\circ} \mathrm{C}$; after quenching the reaction, cells were harvested immediately or after a $20,40,90$ or 240 min chase (Fig. 2B). PAM-1 internalized into HEK293 cells was not rapidly degraded; more than two thirds of the PAM-1 biotinylated on the cell surface was recovered intact after a $4 \mathrm{~h}$ chase (Fig. 2B). Earlier studies using immunoprecipitation to quantify PAM-1 after pulse labeling with $\left[{ }^{35}\right.$ S]Methionine (Tausk et al., 1992) also indicated that PAM-1 turns over slowly in HEK293 cells.

In AtT-20 cells, the endosomal processing of internalized PAM-1 involves a proteolytic cleavage that separates soluble PAM (SPAM) from the transmembrane domain/cytoplasmic domain of PAM (Fig. 2B). Analysis of the chase media from surface biotinylated PAM-1 HEK293 cells revealed the presence of a similar PAM protein (Fig. 2B); after a $4 \mathrm{~h}$ chase, biotinylated sPAM accounted for $13 \%$ of the pulse-labeled PAM-1.

\subsection{PAM containing endosomes make frequent tubular contacts}

We next followed the internalization of PAM/Ab complexes with live cell video imaging. PAM/Ab containing endosomes displayed rapid saltatory movements and frequent, often prolonged contacts with each other (Movie 1). PAM/Ab containing tubules connecting endosomes were also frequently observed. In addition, apparent movement of detached tubules between endosomes could be detected (Fig. 3).

Similar images were not seen by conventional electron microscopy. We therefore utilized high pressure freezing, which allows instant preservation of membrane structures. With this method we could detect tubular contacts between endosomes and direct apposition of multivesicular body membranes (Fig. 4A-E). This method also revealed close contacts between multivesicular bodies and lysosomes, which in these preparations appear as larger and more electron lucent structures than in conventional transmission electron microscopy (Murk et al., 2003). We did not detect tubular contacts between lysosomes; direct fusion connecting lysosomes could sometimes be seen Fig. 4F-I).

\subsection{PAM containing endosomes of different age make frequent contacts and exchange material}

We next asked whether the presence of tubular contacts between PAM/Ab containing endosomes allowed the exchange of material. PAM-1 HEK293 cells were first incubated with Alexa 555 conjugated PAM antibody (older endosomes); after a 20 min chase, the same cells were incubated with Alexa 488 conjugated PAM antibody (younger endosomes). This methodology was made possible by the marked stability of the internalized PAM/Ab complexes. We observed frequent contacts and material exchange between younger and older endosomes whether examined immediately after labeling the young endosomes or after an additional $10 \mathrm{~min}$ of chase (Movie 2 and Fig. 5).

\subsection{PAM and mannose-6-phosphate receptor are internalized by the same population of endosomes}

The mannose-6-phosphate receptor (MPR) transports lysosomal enzymes from the TGN to late endosomes. Some of the cation-independent MPR is also routed to the cell mem- 
A.
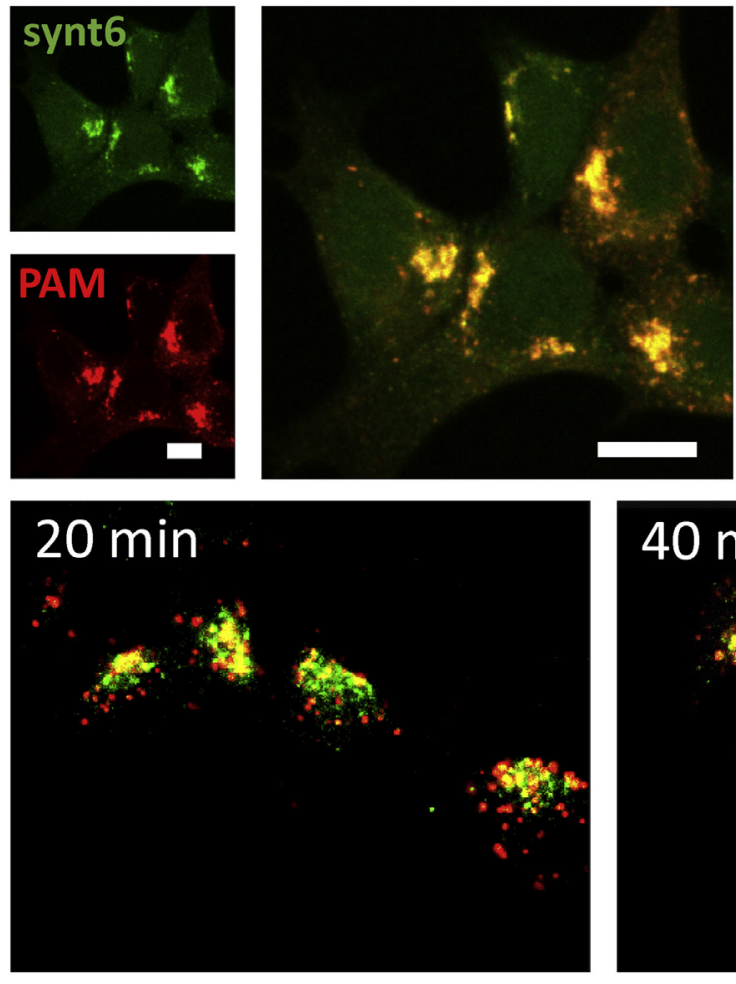

B.
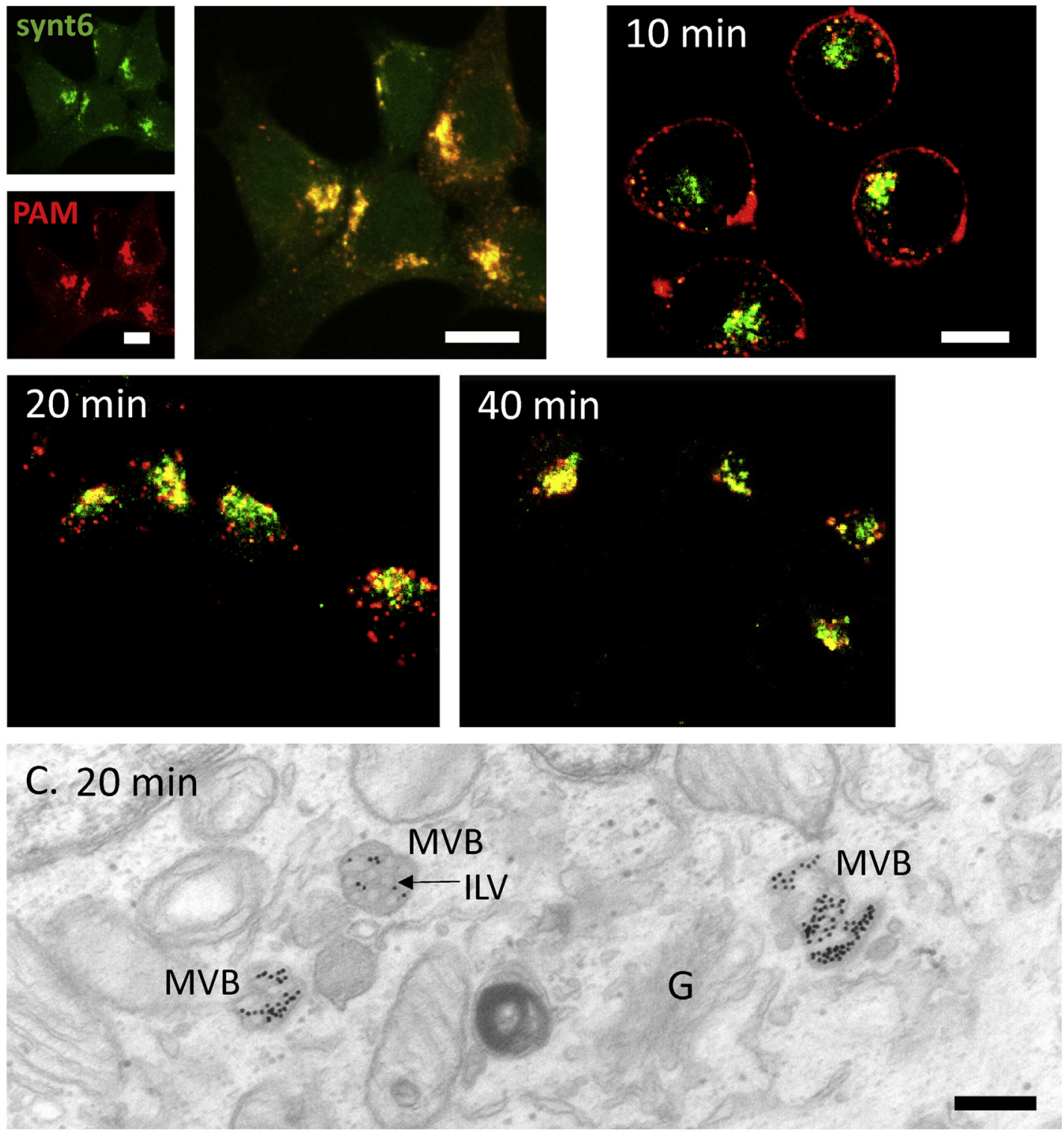

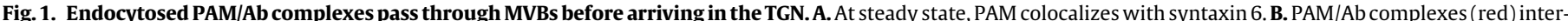

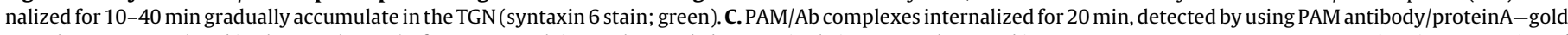

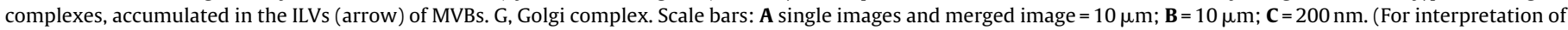
the references to colour in this figure legend, the reader is referred to the web version of this article.)

brane, where it acts as an insulin-like growth factor-II receptor (Macdonald et al., 1988; Morgan et al., 1987; Oshima et al., 1988). From the cell membrane, MPR is internalized and returned to the TGN via several distinct routes from early and late endosomes (Bonifacino and Rojas, 2006; Johannes and Popoff, 2008). By again using antibody labeling, we simultaneously followed the uptake of PAM/Ab complexes and MPR/Ab complexes. During the initial 10 min of uptake, a proportion of the internalized MPR was rapidly collected in the TGN. At later time points, both PAM/Ab complexes and MPR/Ab complexes continually accumulated in the TGN (Fig. 6A-B). We quantified co-localization and found that over $90 \%$ of the labeled endosomes contained both PAM and MPR Ab complexes after 10 and 20 min of uptake (Fig. $6 \mathbf{C}$ ).

For electron microscopy, we labeled MPR and PAM at the cell membrane with antibodies linked to a species specific secondary antibody and conjugated to 5 or $10 \mathrm{~nm}$ gold particles. Using this approach, we detected PAM and MPR Ab complexes in the same multivesicular bodies, even on the same intralumenal vesicles (Fig. 6D).

\subsection{PAM and EGF are internalized by the same population of endosomes}

EGF signaling at the plasma membrane is terminated by the carefully regulated internalization of EGF/EGF receptor complexes followed by their incorporation into the ILVs of MVBs and subsequent degradation (Tomas et al., 2014). Alexa 488 linked to EGF and Alexa 555 linked to PAM antibody were simultaneously internalized by PAM-1 HEK293 cells. Pearson coefficients for the co-localization of fluorophores were calculated after chase times of 10,20 and $40 \mathrm{~min}$; at each time, they demonstrated almost $100 \%$ overlap (Fig. 7A).

Given the very different fates of these cargos, this result was unexpected. As these observations were obtained from fixed cells, 
A.

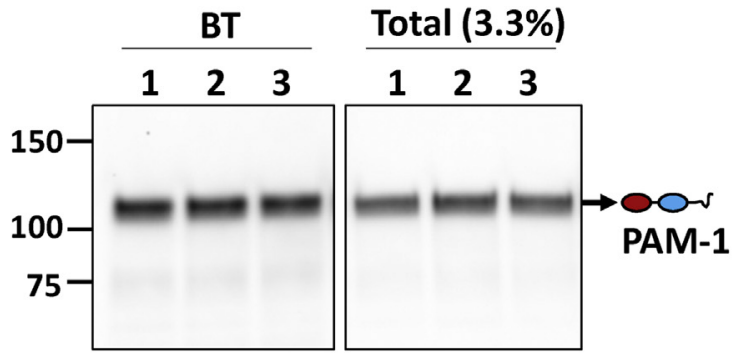

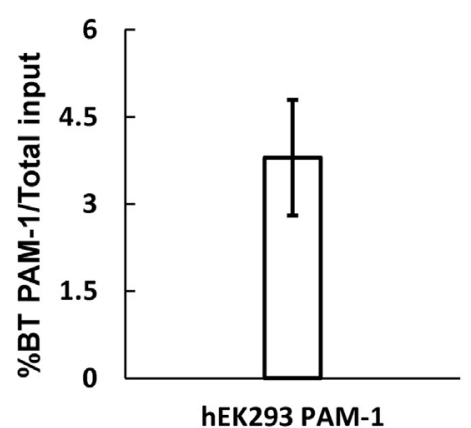
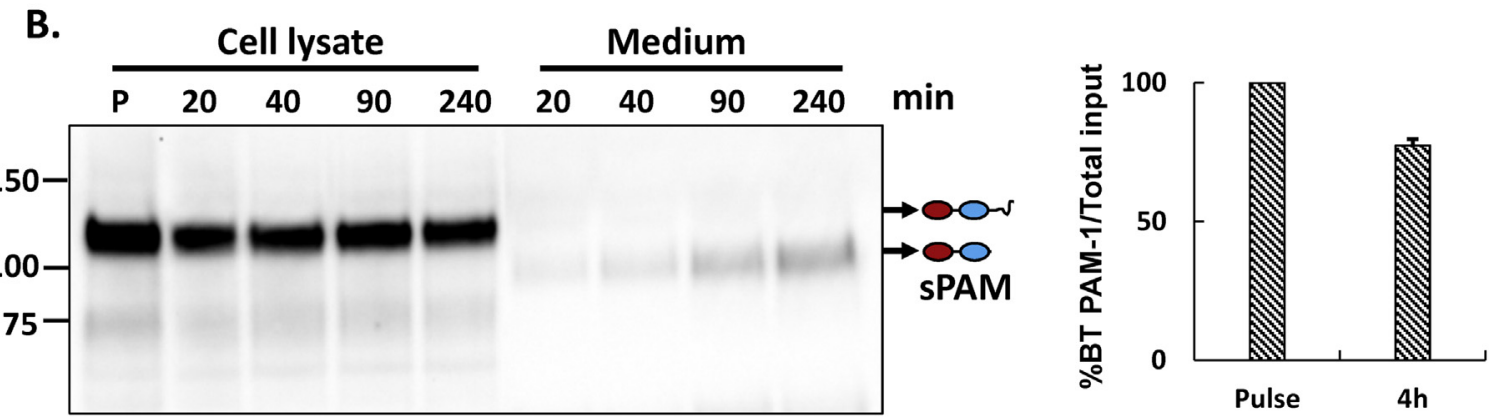

Fig. 2. Internalized biotinylated PAM-1 is stable. A. PAM-1 HEK293 cells chilled to $4{ }^{\circ} \mathrm{C}$ were exposed to cell impermeant activated biotin for 10 min; the reaction was quenched and biotinylated proteins isolated from cell lysates (BT) were fractionated and probed for PAM using affinity purified antibody specific for the C terminus of PAM; input samples (Total) representing 3.3\% as much material were analyzed simultaneously. The bar graph shows the ratio of biotinylated PAM-1 to total PAM-1 at steady state. The values represent the average \pm SD of triplicate samples from two experiments. B. PAM-1 HEK293 cells kept at $37^{\circ} \mathrm{C}$ were incubated with cell impermeant biotin for $10 \mathrm{~min}$; the reaction was quenched and cells were harvested (P; pulse) or chased in growth medium for the indicated amount of time; biotinylated proteins were isolated from cell lysates and spent media, fractionated, and probed for PAM using either the CD antibody (cell extracts) or exon 16 antibody (medium); input samples (not shown) were analyzed simultaneously. Soluble bifunctional PAM (SPAM) was the major biotinylated product secreted by PAM-1 hEK293 cells. Biotinylated PAM-1 remaining at the end of chase period $(4 \mathrm{~h})$ was plotted as a percentage of the total present after the pulse.
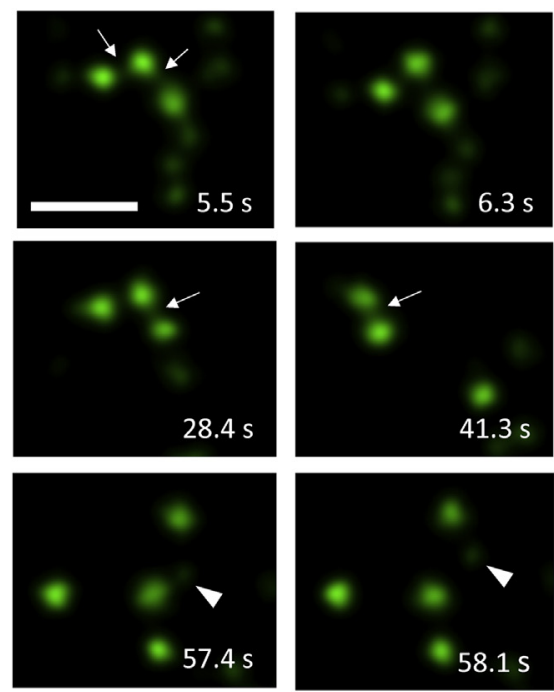
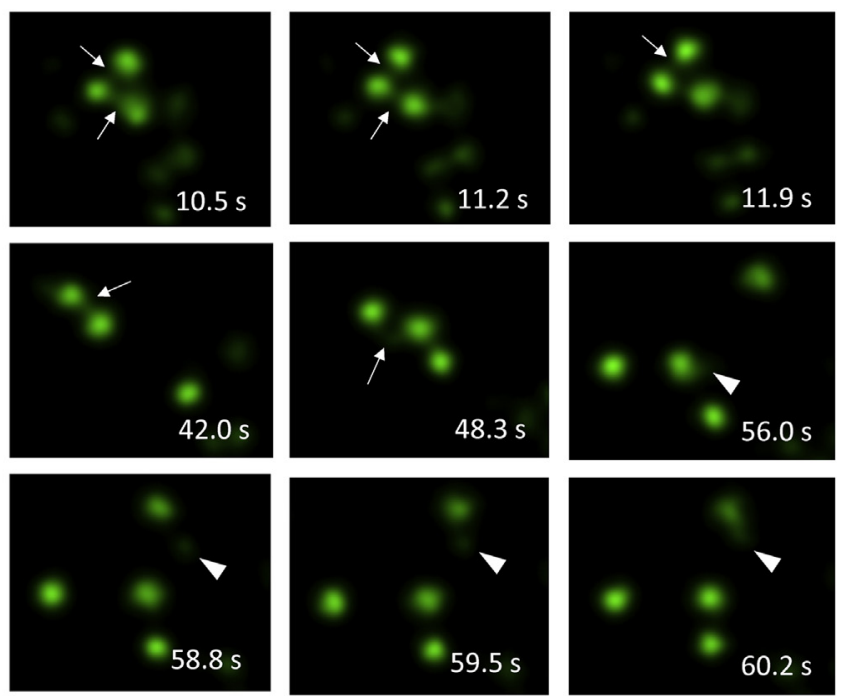

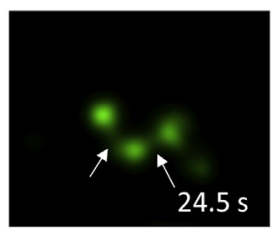

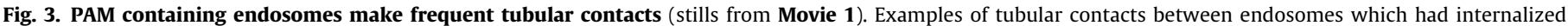
$\mathrm{PAM} / \mathrm{Ab}$ for $40 \mathrm{~min}$ (arrows). At arrowheads, tubule detaches and migrates to contact another PAM containing endosome. $\mathrm{Scale}$ bar $=2 \mu \mathrm{m}$.

we repeated the experiment on video images obtained from live cells. Analyzed in this manner, we found a less than $50 \%$ overlap of the fluorophores detecting PAM and EGF. There was a slight decrease in co-localization at $40 \mathrm{~min}$; analysis of Mander's coefficients (showing the intensity of PAM/Ab complex fluorescence overlapping EGF fluorescence in relation to total PAM fluorescence) showed that this was due to a significant decrease in the propor- tion of PAM overlapping EGF, in agreement with degradation of EGF (Fig. 7B).

When individual endosomes in live video images were analyzed, we found that $80 \%$ contained both PAM/Ab complexes and fluorescently tagged EGF (Fig. 7C). Together, these results suggest that most endosomes contain both cargos but largely in different domains; the formaldehyde fixation protocol used apparently allowed mixing of these domains. 

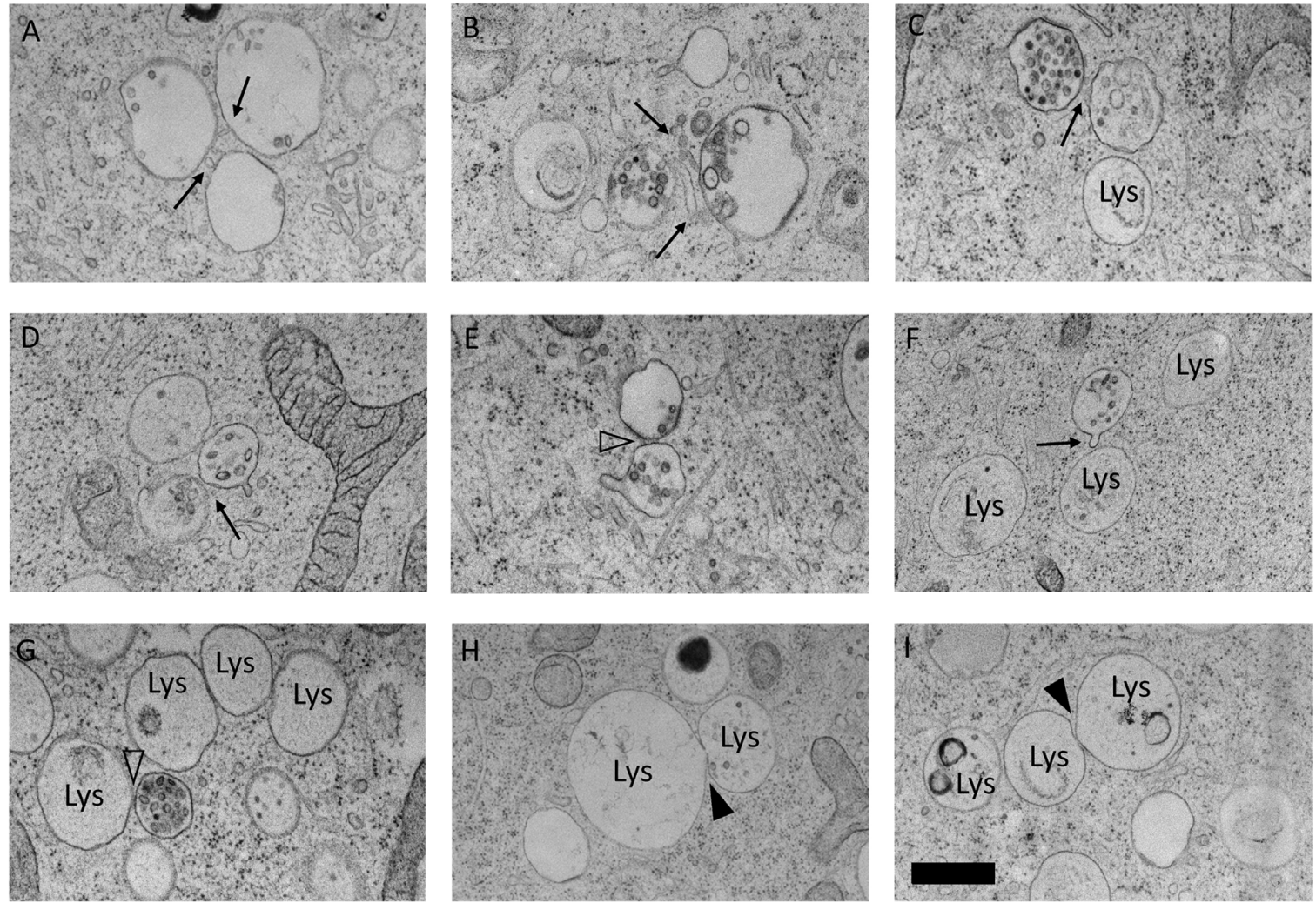

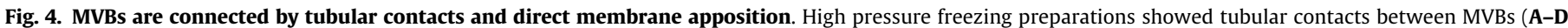

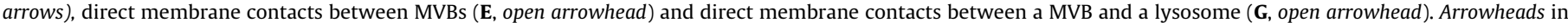
H-I show fusion between lysosomes. Scale bar $=500 \mathrm{~nm}$.
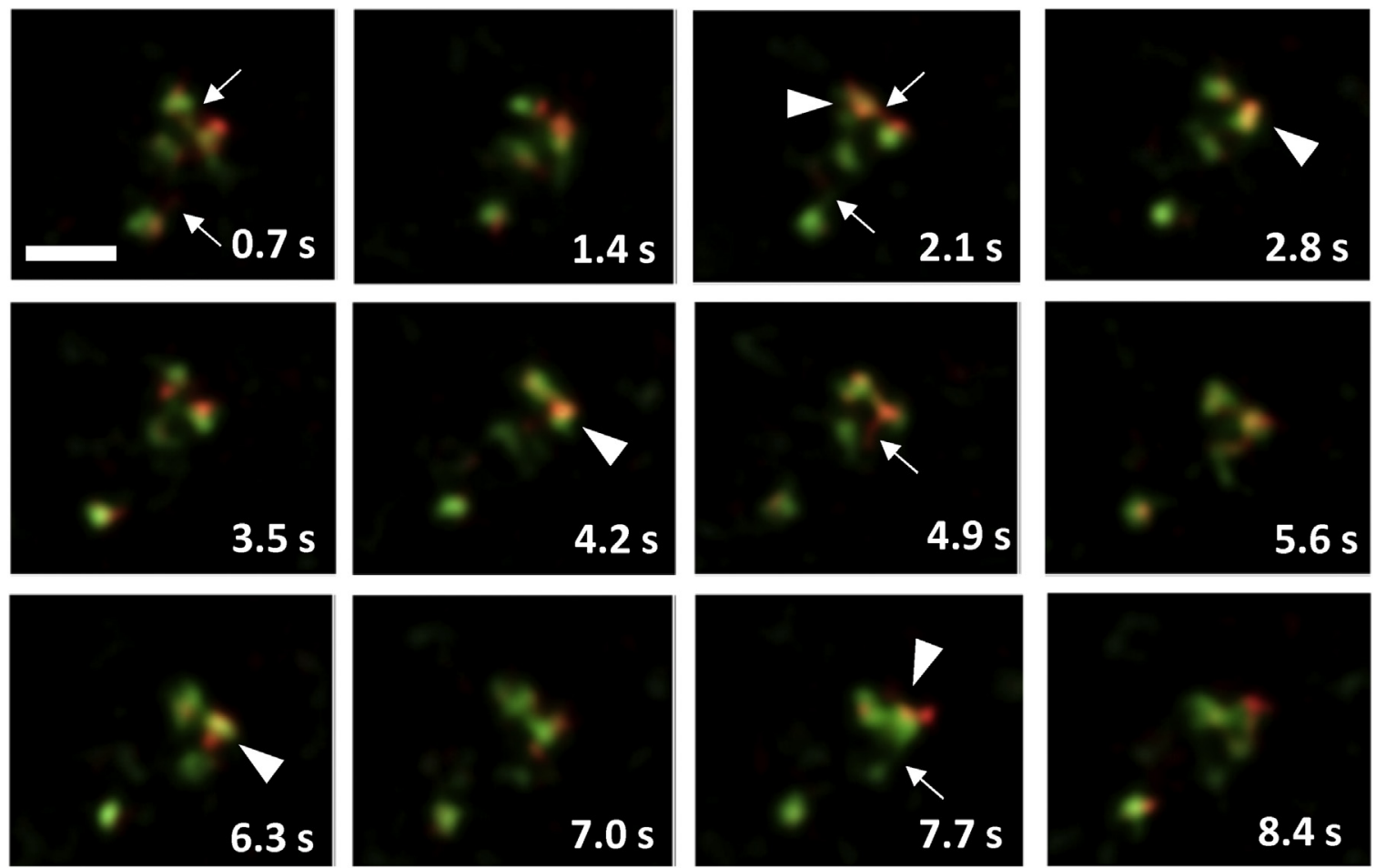

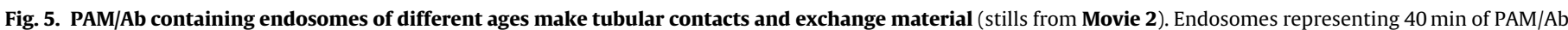

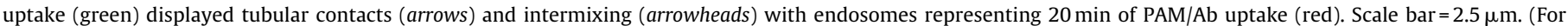
interpretation of the references to colour in this figure legend, the reader is referred to the web version of this article). 
A.
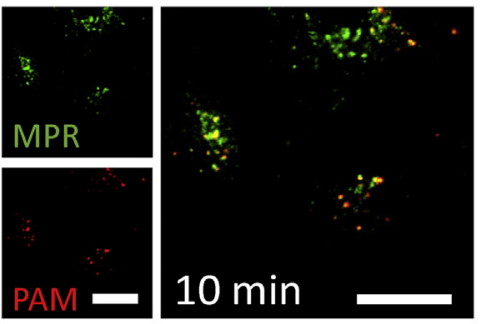

B.
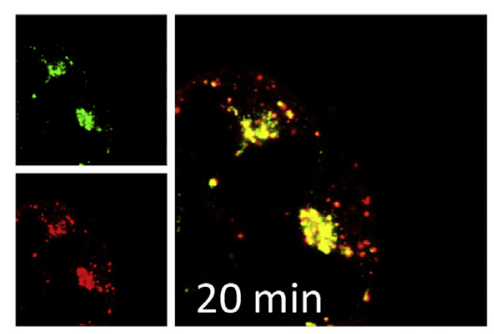
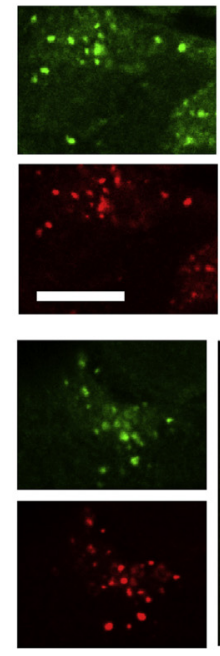
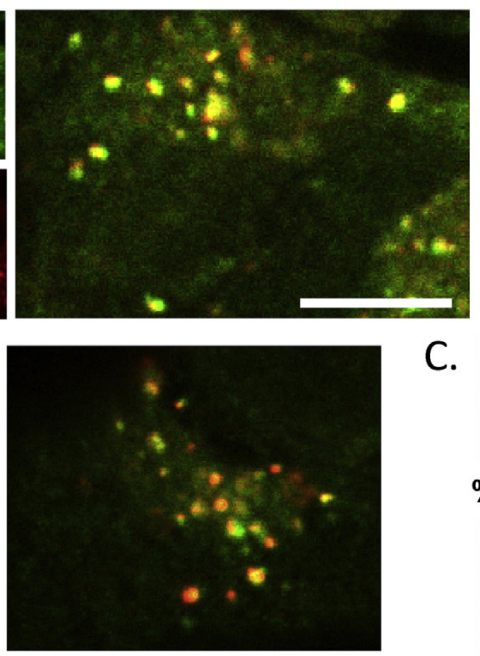

C.

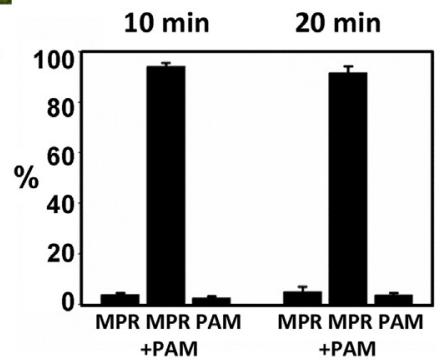

D.

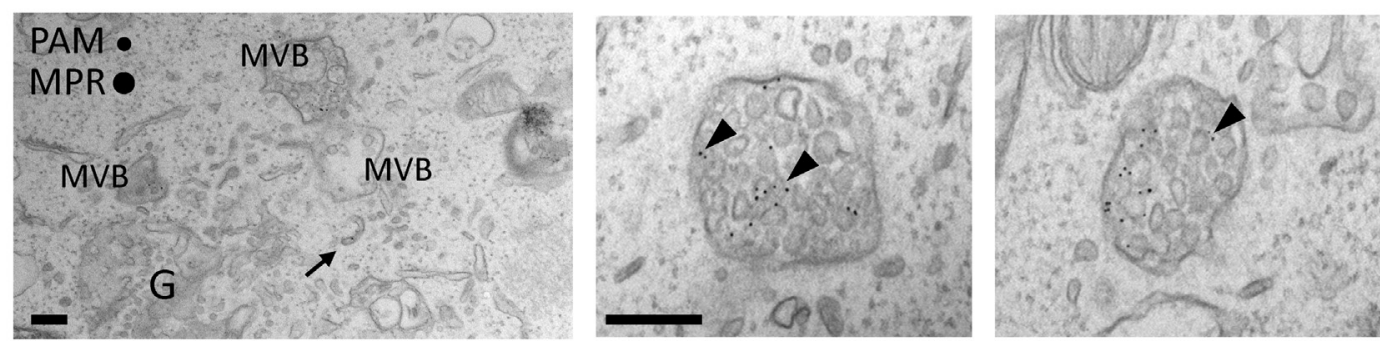

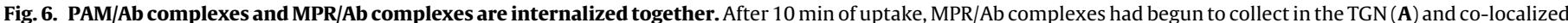

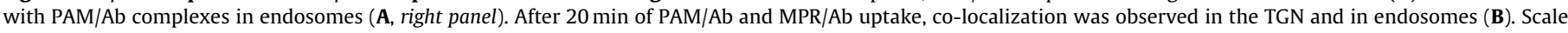

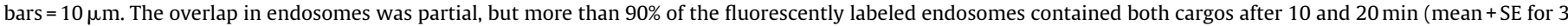

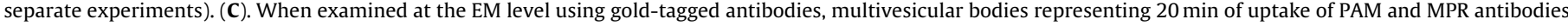

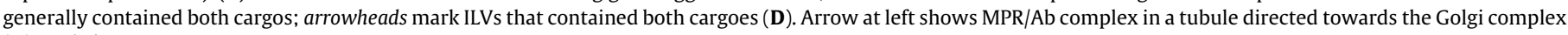
(G). Scale bars $=200 \mathrm{~nm}$.

We next studied the dynamics of PAM/Ab and fluorescently tagged EGF containing endosomal domains in live cell videos. Especially at 10 min of uptake, these domains were highly mobile. At 20 min after uptake, we also saw frequent contacts, exchange of material and transient co-localization of PAM/Ab complexes and fluorescently tagged EGF (Movies 3, 4 Fig. 8A-B). Multivesicular bodies made two types of contact: about half of the contacts lasted for a second or less while the other half lasted substantially longer (2-21 s) (Fig. 8C). Endosomes containing PAM/Ab complexes internalized for $20 \mathrm{~min}$ made an average of $5.2+0.4$ contacts/minute with other endosomes of the same age, with a mean duration of $2.9+0.4 \mathrm{~s}$. This means that a PAM/Ab complex containing endosome (identified as multivesicular bodies at the ultrastructural level) was connected to another endosome of the same age for approximately $15 \mathrm{~s} / \mathrm{min}$, or $25 \%$ of the time.

Electron microscopy confirmed the co-localization of PAM/Ab complexes and EGF in most multivesicular bodies (Fig. 9). The $\mathrm{PAM} / \mathrm{Ab}$ complexes and EGF were separated, but were also associated with the same intralumenal vesicles. Degradation of EGF, evident as aggregation of EGF-derived gold particles, started in organelles that still contained intralumenal vesicles (Fig. 9E and F).

\subsection{PAM containing endosomes make frequent prolonged contacts with lysosomes}

The dynamics of contact between PAM/Ab complex containing endosomes and lysosomes were studied with the same approach. Lysosomes were loaded by incubating the cells with fluorescently tagged dextran for $4 \mathrm{~h}$ followed by a $1 \mathrm{~h}$ chase in medium lacking any fluorophore; the cells were then incubated with fluorescently tagged PAM antibody (Movie 5, Fig. 10A). Endosomes representing 20 min of PAM/Ab uptake made frequent contacts with lysosomes; on average, endosomes made $5.8+0.4$ contacts per minute, with a mean duration of $2.3+0.2 \mathrm{~s}$ (Fig. 10C). The frequency and duration of contacts did not differ significantly from endosome-endosome contacts analyzed at the same chase time. An endosome representing 20 min of PAM/Ab uptake was thus in contact with a lysosome for an average of $13 \mathrm{~s} / \mathrm{min}$. Remarkably, endosomes representing 10 min of PAM/Ab uptake displayed contacts with lysosomes with similar frequency (Movie 6, Fig. 10B). Nevertheless, surface biotinylation demonstrated that internalized PAM had a half-life substantially longer than $4 \mathrm{~h}$.

\section{Discussion}

\subsection{PAM/Ab complexes, MPR/Ab complexes and EGF travel together}

There is evidence for different types of MVBs (White et al., 2006; Babst, 2011) and subtypes of ILVs (Edgar et al., 2014). For the three cargos studied, we did not see any indication of their separation into subtypes of MVBs. The extensive overlap of internalized PAM/Ab complexes and MPR/Ab complexes as well as PAM/Ab complexes and fluorescently tagged EGF indicated that all three cargos were transported by the same type of MVBs. We could even detect colocalization of PAM/Ab complexes and MPR/Ab complexes as well as PAM/Ab complexes and EGF on the same ILVs. The staining intensity was, however, too low for a reliable classification of individual 

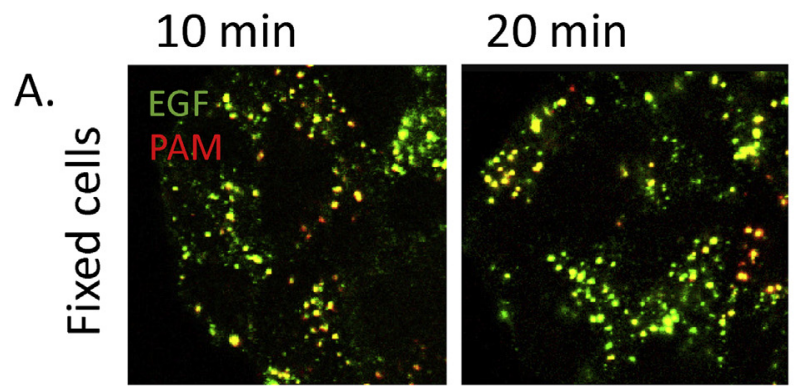

\section{$40 \mathrm{~min}$}

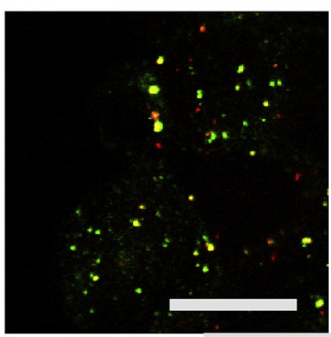

B.

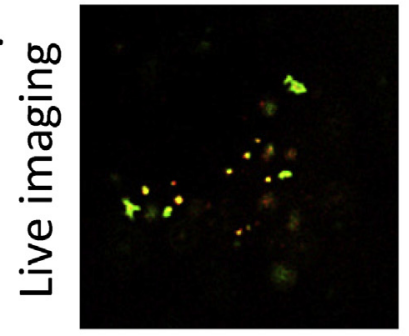

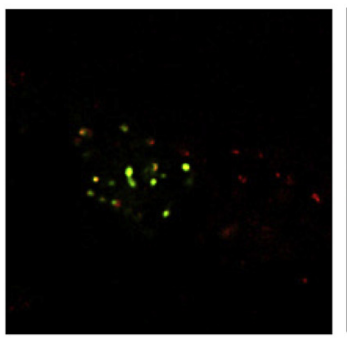

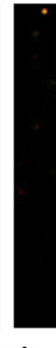

c.
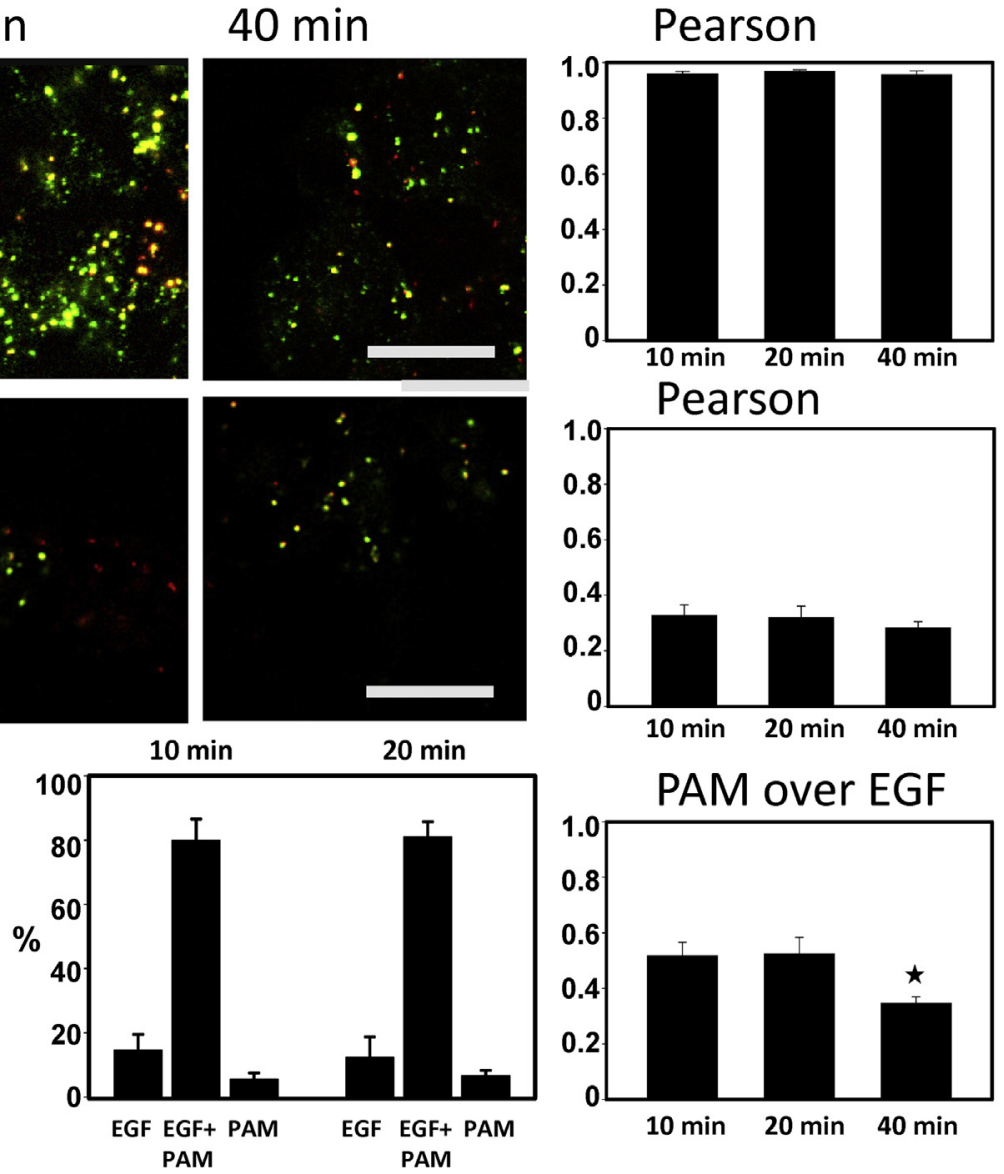

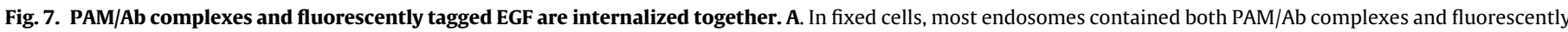

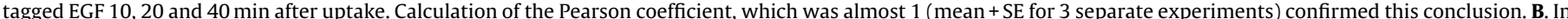

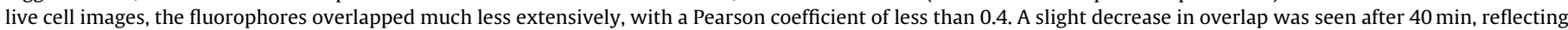

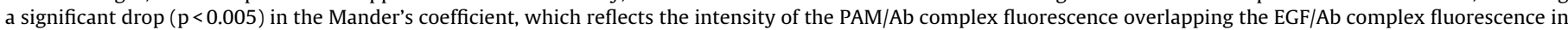

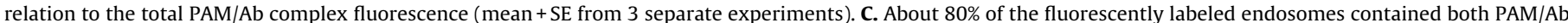
complexes and fluorescently tagged EGF at 10 and $20 \mathrm{~min}$. Scale bars $=10 \mu \mathrm{m}$.

A.
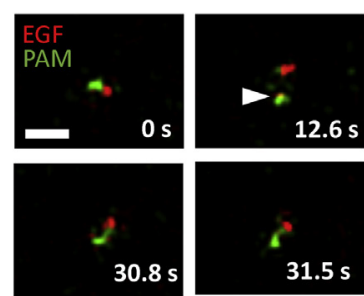

B.
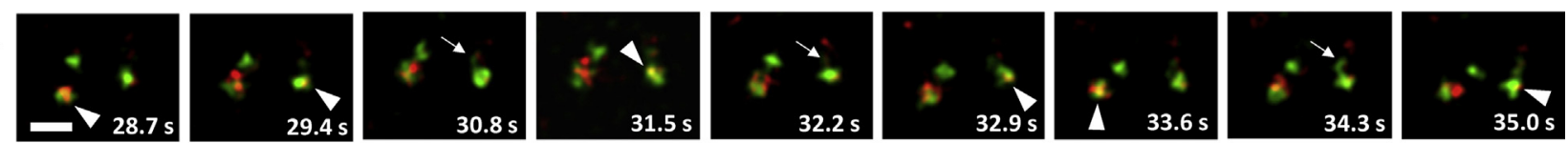
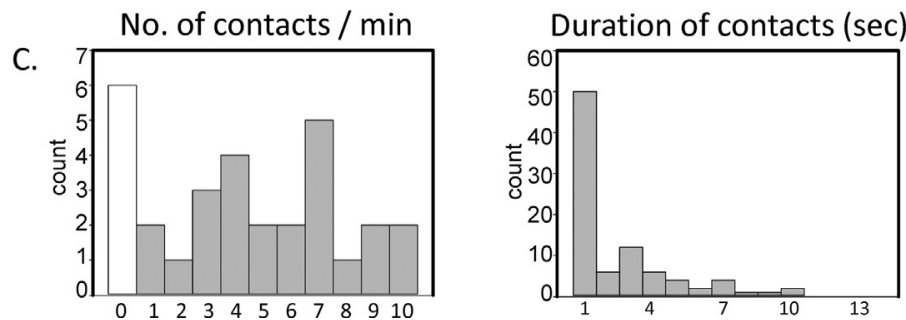

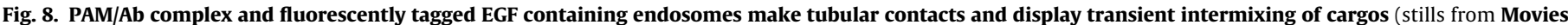

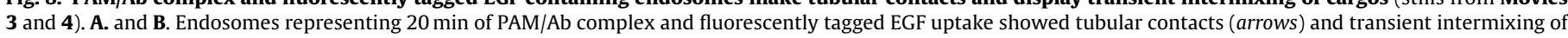

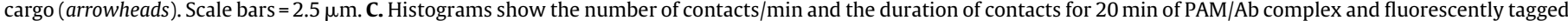
EGF uptake (for clarity, two longer durations, 16 and $21 \mathrm{~s}$, were not included) (30 endosomes, 90 contacts from 3 separate experiments). 

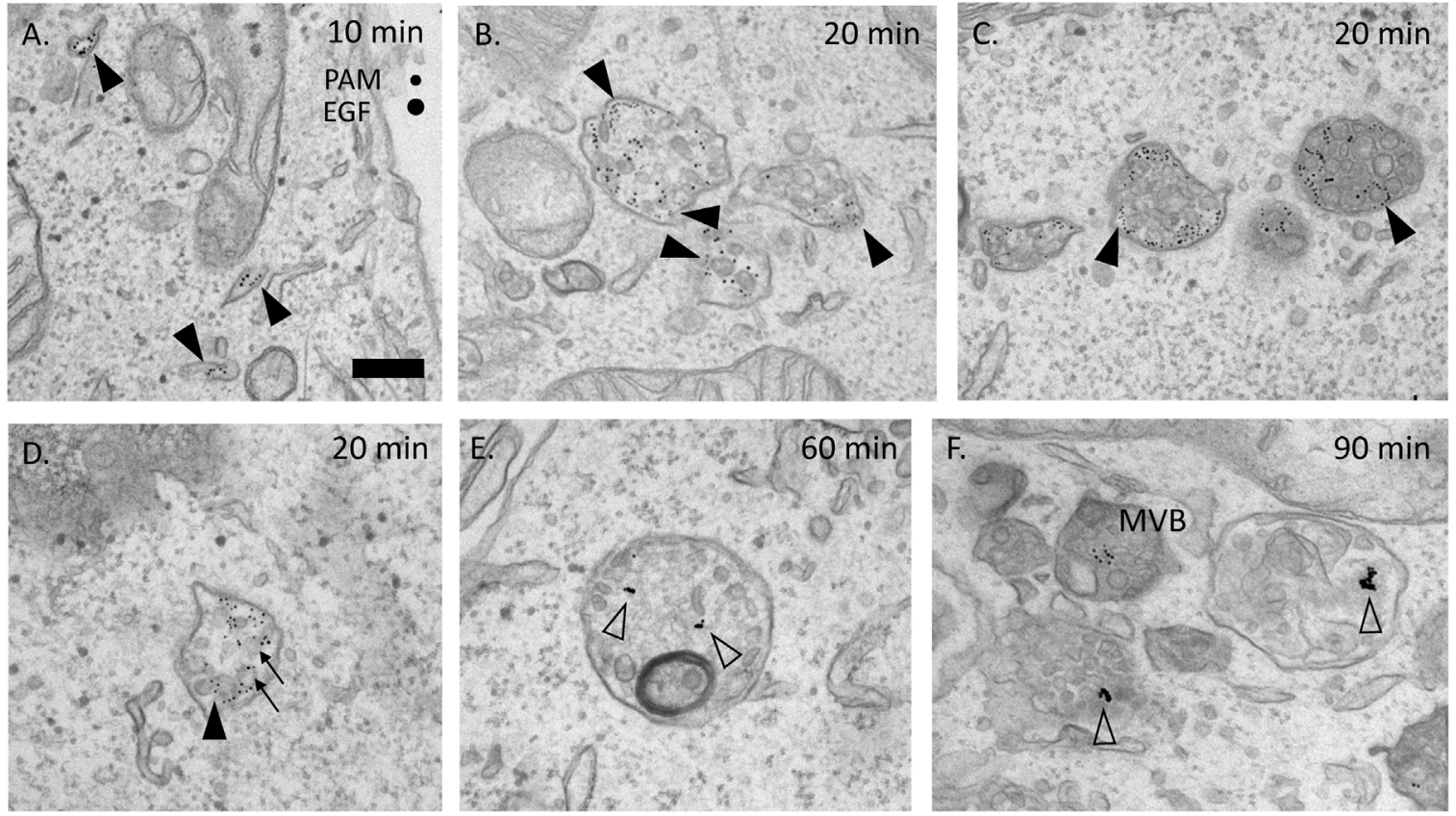

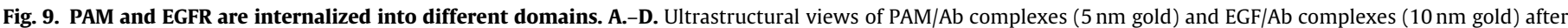

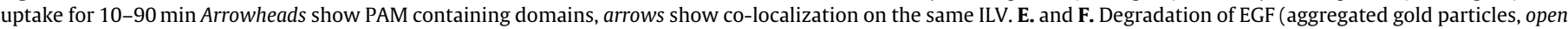
arrowheads) began in structures still containing ILVs. Scale bars $=200 \mathrm{~nm}$.

A.

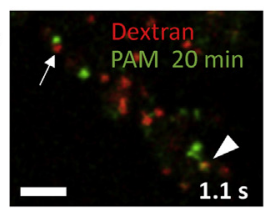

B.
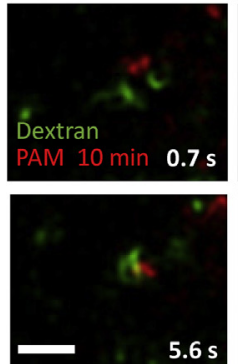

No. of contacts / $\mathrm{min}$

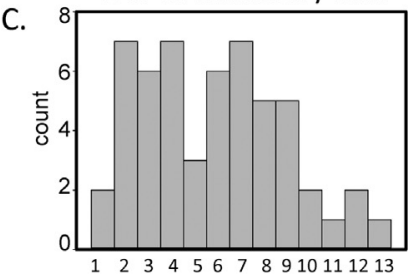

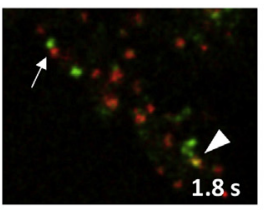
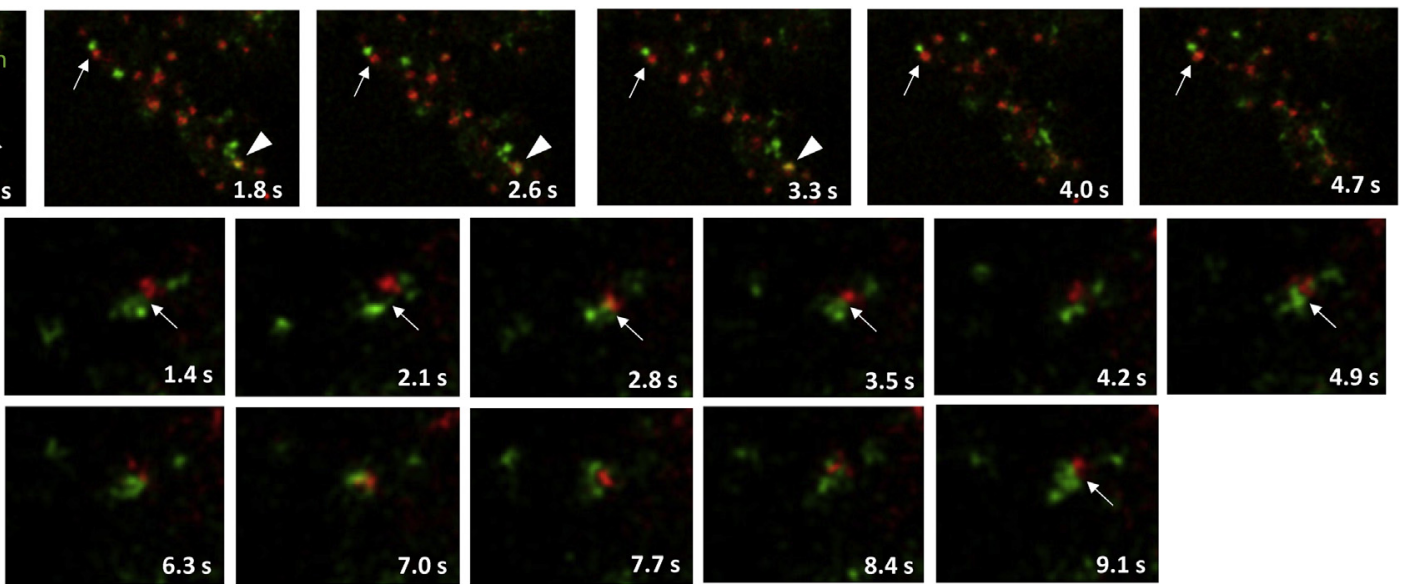

Duration of contacts (sec)

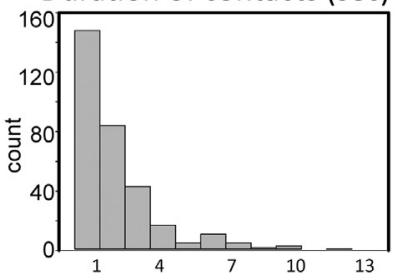

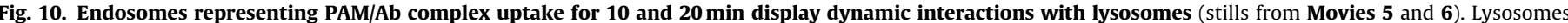

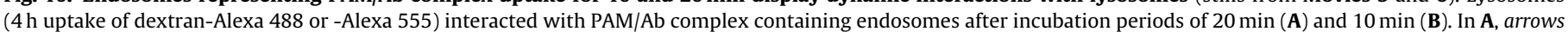

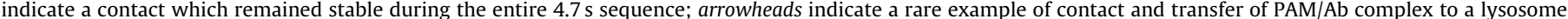

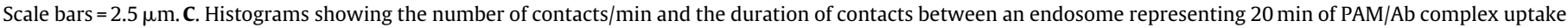
and a lysosome (for clarity, three longer durations, 17, 19 and 21 s, were not included) (55 endosomes, 323 contacts from 3 separate experiments).

ILVs and the proportion of ILVs carrying both cargos could not be determined in this study.

\subsection{Multivesicular bodies form a dynamic network}

The formation of MVBs is a gradual process during which the maturation of early endosomes terminates the extension of recy- cling tubules and increases the formation of ILVs. Extension of tubules mediating MVB-TGN transport continues throughout MVB maturation (Huotari and Helenius, 2011).

This study shows that live cell imaging with high frequency and high pressure freezing preparation for electron microscopy enable detection of tubular contacts and material exchange between PAM containing MVBs, features not well preserved by conventional fix- 
ation. We found that MVBs labeled 20 min earlier were in contact with MVBs of the same age approximately $25 \%$ of the time. A similar frequency of contacts was observed when evaluating contacts between younger and older endosomes, suggesting MVBs labeled 20 min earlier are in contact with other endosomes most of the time. To this can be added the fact that maturing endosomes maintain close contact with ER membranes, as shown for Cos-7, DKO and U2OS cells (Friedman et al., 2013; Dong et al., 2016). In addition, MVB-ER membrane interaction is crucial for EGFR degradation (Eden et al., 2010, 2016). Instead of individually maturing along microtubule tracks, multivesicular bodies probably depend on crosstalk with other multivesicular bodies and the ER for their maturation.

\subsection{Lysosomes interact continuously with endosomes of different ages}

The mechanism for delivery of ILVs from MVBs to lysosomes remains obscure: it could occur through fusion leading to the formation of a hybrid organelle, through maturation of a MVB into a lysosome, through tubular contacts, through kiss-and-run contacts or through kiss-and-linger contacts (Bright et al., 2005; Gan et al., 2009; Pryor and Luzio, 2009). The lysosome has generally been considered the end point of endosomal trafficking and the special composition of the lysosomal membrane as a shield against the proteolytic enzymes harbored in this organelle. This study shows contacts between MVBs labeled 20 min earlier and lysosomes with the same frequency and duration observed for contacts amongst MVBs. Contacts between $10 \mathrm{~min}$ endosomes and lysosomes seem equally frequent. Instead of simply mediating cargo transfer, the extensive membrane connections between both early and late endosomes/MVBs and lysosomes observed in this study may serve functions similar to those attributed to membrane contact sites between other membrane compartments such as Golgi-ER, lipid droplet-ER, mitochondrion-ER contacts (Gallo et al., 2016).

\subsection{Endocytic trafficking of PAM through multivesicular bodies is similar in HEK293 and neuroendocrine cells}

Because of its essential role in the production of many neuropeptides, research on PAM trafficking has focused on neuroendocrine cells. Pulse/chase metabolic labeling studies demonstrate prohormone convertase mediated cleavage of PAM in neuroendocrine cells, producing soluble PHM and soluble PAL that are secreted along with their product peptides. Expression of soluble PHM in neuroendocrine cells leads to its efficient storage in secretory granules. In contrast, expression of soluble PHM in cells that do not produce secretory granules results in its rapid secretion, via the constitutive pathway.

Early studies revealed an essential role for trafficking determinants in the cytosolic domain of PAM. In both neuroendocrine cells and cells lacking secretory granules, PAM-1 is largely localized to the TGN (HEK, CHO, AtT-20, neurons, pituitary endocrine cells, atrial cardiomyocytes) and its endocytic trafficking is strikingly similar. Neuroendocrine cells are known to recycle phogrin and several other secretory granule membrane proteins. The EM images provided here demonstrate that PAM-1 internalized from the surface of HEK293 cells is rapidly trafficked into intraluminal vesicles, as observed previously for AtT-20 corticotrope tumor cells. Surface biotinylation experiments demonstrate that PAM- 1 that enters the endocytic pathway in HEK293 cells is remarkably stable, despite its presence in ILVs. Consistent with its localization in ILVs, PAM has been detected in exosomes (secreted ILVs) isolated from saliva, urine and SCC61 tumor cells (Sinha et al., 2016).

As shown earlier in other cell types, internalized PAM (Bäck et al., 2010) and internalized MPR (Griffiths et al., 1990; Kobayashi et al., 1998; Arighi et al., 2004) both accumulate in ILVs in HEK293 MVBs. Both internalized proteins are quite stable and are largely returned to the TGN. The retrograde transport of both proteins requires that they be sorted away from proteins destined for degradation; for MPR, many of the steps in this retrograde pathway have been well characterized (Bonifacino and Rojas, 2006; Johannes and Popoff, 2008). For both proteins, one key step is poorly understood; in order to return to the TGN, PAM and MPR must exit from ILVs. Reinsertion probably occurs through back fusion of ILVs (Bissig and Gruenberg, 2014), a route hijacked by viruses (Uchil and Mothes, 2005; Luyet et al., 2008), but the mechanism has not yet been explored.

With its recent identification in Chlamydomonas reinhardtii, a unicellular green alga, it is clear that PAM is an ancient enzyme, perhaps present in the last eukaryotic common ancestor (Kumar et al., 2016b). Its requirement for copper, ascorbic acid, low pH and molecular oxygen were presumably part of its ancient role. Characterization of CrPAM led to the discovery that PAM is present on the surface of its motile cilia (Kumar et al., 2016a) and is also present in motile and non-motile cilia in mammals. Chlamydomonas release ectosomes, topologically very similar to ILVs, from the tips of their flagella (Wood et al., 2013). PAM entry into ILVs and presumed exit from MVBs appears to reflect an ancient function of this highly conserved enzyme.

\section{Acknowledgements}

We thank the Electron Microscopy Unit of the Institute of Biotechnology, University of Helsinki for providing laboratory facilities and the Biomedicum Imaging Unit, especially Mikko Liljeström for help with microscopy. This study was supported by grants from the Academy of Finland (250081 to K.K., 282192, 284667, 272130 to E.I.), Finnish Cultural Foundation, Häme Regional Fund (to K.K.), Finska Läkaresällskapet, the Perklén Foundation (to N.B.), the United States National Institute of Health (DK32949), the Janice and Rodney Reynolds Endowment and the William Beecher Scoville Endowment. The funders played no role in study design, data analysis and interpretation, writing of the manuscript, or the decision to publish the paper.

\section{Appendix A. Supplementary data}

Supplementary data associated with this article can be found, in the online version, at http://dx.doi.org/10.1016/j.ejcb.2017.03.007

\section{References}

Arighi, C.N., Harmell, L.M., Aguilar, R.C., Haft, C.R., Bonifacino, J.S., 2004. Role of the mammalian retromer in sorting of the cation-independent mannose 6-phosphate receptor. J. Cell Biol. 165 (1), 123--133, http://dx.doi.org/10. 1083/jcb.200312055.

Bäck, N., Rajagopal, C., Mains, R.E., Eipper, B.A., 2010. Secretory granule membrane protein recycles through multivesicular bodies. Traffic 11 (7), 972-986, http:/ dx.doi.org/10.1111/j.1600-0854.2010.01066.x.

Babst, M., 2011. MVB vesicle formation: ESCRT-dependent, ESCRT-independent and everything in between. Curr. Opin. Cell Biol. 23 (4), 452--457, http://dx. doi.org/10.1016/j.ceb.2011.04.008.

Biazik, J., Ylä-Anttila, P., Vihinen, H., Jokitalo, E., Eskelinen, E.-L., 2015. Ultrastructural relationship of the phagophore with surrounding organelles. Autophagy 11 (3), 439-451.

Bissig, C., Gruenberg, J., 2014. ALIX and the multivesicular endosome: ALIX in wonderland. Trends Cell Biol. 24 (1), 19-25, http://dx.doi.org/10.1016/j.tcb. 2013.10.009.

Bonifacino, J.S., Rojas, R., 2006. Retrograde transport from endosomes to the trans-golgi network. Nat. Rev. Mol. Cell Biol. 7 (8), 568--579, http://dx.doi.org 10.1038/nrm1985.

Bright, N.A., Gratian, M.J., Luzio, J.P., 2005. Endocytic delivery to lysosomes mediated by concurrent fusion and kissing events in living cells. Curr. Biol. 15 (4), 360-365, http://dx.doi.org/10.1016/j.cub.2005.01.049.

Dong, R., Saheki, Y., Swarup, S., Lucast, L., Harper, J.W., De Camilli, P., 2016. Endosome-ER contacts control actin nucleation and retromer function through 
VAP-dependent regulation of PI4P. Cell 166 (2), 408-423, http://dx.doi.org/10. 1016/j.cell.2016.06.037.

Eden, E.R., White, I.J., Tsapara, A., Futter, C.E., 2010. Membrane contacts between endosomes and ER provide sites for PTP1B-epidermal growth factor receptor interaction. Nat. Cell Biol. 12 (3), 267-272, http://dx.doi.org/10.1038/ncb2026.

Eden, E.R., Sanchez-Heras, E., Tsapara, A., Sobota, A., Levine, T.P., Futter, C.E., 2016. Annexin A1 tethers membrane contact sites that mediate ER to endosome cholesterol transport. Dev. Cell 37 (5), 473-483, http://dx.doi.org/10.1016/j. devcel.2016.05.005.

Edgar, J.R., Eden, E.R., Futter, C.E., 2014. Hrs- and CD63-dependent competing mechanisms make different sized endosomal intraluminal vesicles. Traffic 15 (2), 197-211, http://dx.doi.org/10.1111/tra.12139.

Friedman, J.R., DiBenedetto, J.R., West, M., Rowland, A.A., Voeltz, G.K., 2013. Endoplasmic reticulum-endosome contact increases as endosomes traffic and mature. Mol. Biol. Cell 24 (7), 1030-1040, http://dx.doi.org/10.1091/mbc.E1210-0733.

Gallo, A., Vannier, C., Galli, T., 2016. Endoplasmic reticulum-plasma membrane associations: structures and functions. Annu. Rev. Cell Dev. Biol. 32, 279-301, http://dx.doi.org/10.1146/annurev-cellbio-111315-125024.

Gan, Z., Ram, S., Vaccaro, C., Ober, R.J., Ward, S.E., 2009. Analyses of the recycling receptor, FcRn, in live cells reveal novel pathways for lysosomal delivery. Traffic 10 (5), 600-614, http://dx.doi.org/10.1111/j.1600-0854.2009.00887.x.

Griffiths, G., Matteoni, R., Back, R., Hoflack, B., 1990. Characterization of the cation-independent mannose 6-phosphate receptor-enriched prelysosomal compartment in NRK cells. J. Cell Sci. 95 (3), 441-461.

Gruenberg, J., Stenmark, H., 2004. The biogenesis of multivesicular endosomes. Nat. Rev. Mol. Cell Biol. 5 (4), 317-323, http://dx.doi.org/10.1038/nrm1360.

Huotari, J., Helenius, A., 2011. Endosome maturation. EMBO J. 30 (17), 3481-3500, http://dx.doi.org/10.1038/emboj.2011.286.

Johannes, L., Popoff, V., 2008. Tracing the retrograde route in protein trafficking. Cell 135 (7), 1175-1187, http://dx.doi.org/10.1016/j.cell.2008.12.009.

Kleijmeer, M., Ramm, G., Schuurhuis, D., Griffith, J., Rescigno, M. Ricciardi-Castagnoli, P., Geuze, H.J., 2001. Reorganization of multivesicular bodies regulates MHC class II 11 antigen presentation by dendritic cells. J. Cell Biol. 155 (1), 53--63, http://dx.doi.org/10.1083/jcb.200103071.

Kobayashi, T., Stang, E., Fang, K.S., De Moerloose, P., Parton, R.G., Gruenberg, J., 1998. A lipid associated with the antiphospholipid syndrome regulates endosome structure and function. Nature 392 (6672), 193-197, http://dx.doi. org/10.1038/32440.

Kumar, D., Mains, R.E., Eipper, B.A., 2016a. From POMC and $\alpha$-MSH to PAM, molecular oxygen, copper and vitamin C. J. Mol. Endocrinol. 56 (4), T63-T76, http://dx.doi.org/10.1530/JME-15-0266.

Kumar, D., Blaby-Haas, C.E., Merchant, S.S., Mains, R.E., King, S.M., Eipper, B.A. 2016b. Early eukaryotic origins for cilia-associated bioactive peptide amidating activity. J. Cell Sci. 129 (5), 943-956, http://dx.doi.org/10.1242/jcs.177410.
Luyet, P.-, Falguières, T., Pons, V., Pattnaik, A.K., Gruenberg, J., 2008. The ESCRT-I subunit TSG101 controls endosome-to-cytosol release of viral RNA. Traffic 9 (12), 2279-2290, http://dx.doi.org/10.1111/j.1600-0854.2008.00820.x.

Macdonald, R.G., Pfeffer, S.R., Coussens, L., Tepper, M.A., Brocklebank, C.M., Mole, J.E., Ullrich, A., 1988. A single receptor binds both insulin-like growth factor Il and mannose-6-phosphate. Science 239 (4844), 1134-1137.

Milgram, S.L., Mains, R.E., Eipper, B.A., 1993. COOH-terminal signals mediate the trafficking of a peptide processing enzyme in endocrine cells. J. Cell Biol. 121 (1), 23-36.

Morgan, D.O., Edman, J.C., Standring, D.N., Fried, V.A., Smith, M.C., Roth, R.A., Rutter, W.J., 1987. Insulin-like growth factor II receptor as a multifunctional binding protein. Nature 329 (6137), 301-307.

Murk, J.L.A.N., Posthuma, G., Koster, A.J., Geuze, H.J., Verkleij, A.J., Kleijmeer, M.J., Humbel, B.M., 2003. Influence of aldehyde fixation on the morphology of endosomes and lysosomes: quantitative analysis and electron tomography. J. Microsc. 212 (1), 81-90, http://dx.doi.org/10.1046/j.1365-2818.2003.01238.x.

Oshima, A., Nolan, C.M., Kyle, J.W., Grubb, J.H., Sly, W.S., 1988. The human cation-independent mannose 6-phosphate receptor. Cloning and sequence of the full-length cDNA and expression of functional receptor in cos cells. J. Biol. Chem. 263 (5), 2553--2562.

Pryor, P.R., Luzio, J.P., 2009. Delivery of endocytosed membrane proteins to the lysosome. Biochim. Biophys. Acta-Mol. Cell Res. 1793 (4), 615-624, http://dx. doi.org/10.1016/j.bbamcr.2008.12.022.

Sinha, S., Hoshino, D., Hong, N.H., Kirkbride, K.C., Grega-Larson, N.E., Seiki, M., Weaver, A.M., 2016. Cortactin promotes exosome secretion by controlling branched actin dynamics. J. Cell Biol. 214 (2), 197--213, http://dx.doi.org/10. $1083 /$ jcb.201601025.

Tausk, F.A., Milgram, S.L., Mains, R.E., Eipper, B.A., 1992. Expression of a peptide processing enzyme in cultured cells: truncation mutants reveal a routing domain. Mol. Endocrinol. 6 (12), 2185-2196, http://dx.doi.org/10.1210/mend. 6.12.1491698.

Tomas, A., Futter, C.E., Eden, E.R., 2014. EGF receptor trafficking: consequences for signaling and cancer. Trends Cell Biol. 24 (1), 26--34, http://dx.doi.org/10. 1016/j.tcb.2013.11.002.

Uchil, P., Mothes, W., 2005. Viral entry: a detour through multivesicular bodies. Nat. Cell Biol. 7 (7), 641-642, http://dx.doi.org/10.1038/ncb0705-641.

White, I.J., Bailey, L.M., Aghakhani, M.R., Moss, S.E., Futter, C.E., 2006. EGF stimulates annexin 1-dependent inward vesiculation in a multivesicular endosome subpopulation. EMBO J. 25 (1), 1--12, http://dx.doi.org/10.1038/sj. emboj.7600759.

Yun, H.-Y., Milgram, S.L., Keutmann, H.T., Eipper, B.A., 1995. Phosphorylation of the cytosolic domain of peptidylglycine $\alpha$-amidating monooxygenase. J. Biol. Chem. 270 (50), 30075-30083, http://dx.doi.org/10.1074/jbc.270.50.30075. 